\title{
Using technology to assist in vocabulary acquisition and reading comprehension
}

\author{
Bozorova N.X. ${ }^{1}$, Salixova Z.A. ${ }^{2}$ \\ ${ }^{1,2}$ Bukhara State University, Uzbekistan \\ Email:bozorova_n@umail.uz
}

\begin{abstract}
The article deals the different type of project-based learning and its pedagogical principles. The importance of project-based learning method and its effectiveness was written here.
\end{abstract}

Keywords: teaching, method, skill, project-based learning, learning technologies.

\section{INTRODUCTION}

The role that vocabulary knowledge plays in second and foreign language acquisition has long been neglected. However, vocabulary is currently receiving increased emphasis in the language-teaching curriculum. This is due to several reasons, such as the influence of comprehension-based approaches to language development, the research efforts of applied linguists, and the exciting possibilities opened-up by the development of computer-based language corpora (Nunan, 1999: 103). Moreover, it is now increasingly pointed out that there is a reciprocal, well-documented relationship between vocabulary knowledge and reading comprehension. Learning vocabulary is an important aspect of L2/FL acquisition and academic achievement and is vital to reading comprehension and proficiency, to which it is closely linked.

Since computers started to be introduced in language learning (and in education in general) people have rightly asked whether the investment we are making in these technologies gives us value for money. As digital technologies have taken a hold in society in general, this particular question is not asked quite so often, but it is still important to make sure that the technologies that we have available are used effectively. People are always tempted to try to make an argument for technologyhaving an impact on the development of pedagogy and in many cases;we can see that the use of technology has enabled teachers to re-think what they are doing. We also see people trying to populate this domain by talking about notions like the 'flipped classroom', ostensibly a methodology that sees input as occurring at 'home'and physical classrooms being used as spaces to explore what has been presented in the input. This is far from being a new idea, but these agendas are pushed for a while and then disappear again. What is a contender for a methodology that is central to the world of technology and language learning is that of blended learning(Motteram and Sharma, 2009). We see this methodology still being developed, but when handled best it is the most likely candidate for a starting point for getting teachers to work with technology in their practice. It is still the case that most teachers work in physical classrooms and looking at ways that these spaces can be augmented with digital technologies is a very good starting point. An extended classroom is one that allows learners to engage in material beyond the regular class period, so while a blended classroom is looking at ways that an activity might be enhanced by a technology, we also see technologies being used to make it possible to cover areas of the curriculum that there is just not enough time for in the busy world of formal education, particularlyin primary and secondary schools. Thorne and Reinhardt (2008) have also proposedthe notion of 'bridging activities', which simplistically is about getting learners to talk about how learners are using technology in their 'out of class lives' in the classroom. Thorne and Reinhardt (2008) are interested in fan fiction, the sort of narrative material that is created around digital gaming. What they propose is that teachers encourage learners to bring this activity into the classroom with them and they use it as the foundations of lessons. The range of technologies what we found was that it was not always the case that new technologies replaced old ones. In some cases, when a newer technology is not always available, what drove teachers' choices was the needs of the lesson and the perceived needs of the learners. 
This graduation work will focus on various possibilities to enhance vocabulary acquisition and reading comprehension with the help of technology. First, it starts with a brief overview of the relationship between vocabulary knowledge and reading comprehension. It continues with a presentation of different technological aids that trigger improved vocabulary acquisition and reading proficiency, with a focus on annotations. Finally, it proposes several teaching principles related to incorporating technology in the language classroom to benefit vocabulary acquisition and reading comprehension.

Reading is an active skill that involves the reader, the text, and the interaction between the two. The acquisition of reading skills is a very important aspect of first (L1) as well as second (L2) or foreign language (FL) literacy. Reading in a L2 or FL is a dynamic and interactive process, during which learners make use of a variety of skills and strategies, combined with background knowledge, L1-related knowledge and real-world knowledge to arrive at an understanding of written material Aebersold and Field, 1997: ix).Many variables play a role in L2/FL reading comprehension. Among the most important are L1 literacy, the use of both top-down and bottom-up strategies, activating background knowledge, the use of various reading skills (e.g. summarizing, identifying the main idea, distinguishing between facts and opinions), and vocabulary knowledge (Egbert, 2005: 21-22).

Several researchers have argued that vocabulary plays a major part in reading proficiency. Thus, Grabe (1991) stresses the important role of vocabulary as predictor of overall reading ability, and Nation (1990) states that effective L2 /FL instruction should also concentrate on cultivating vocabulary (both cited in Anderson, 1999: 25). Chanier and Selva also stress the fact that vocabulary knowledge is a key factor in reading comprehension (1998: 489) and so does Groot (2000), who argues that functional L2 reading proficiency requires mastery of a considerably large number of words.Aside from knowing how to use the appropriate reading strategies, Grabe (1991, as cited in Butler-Pascoe and Wiburg, 2003: 124) argues that fluent L2/FL readers need to know about 2,000 to 7,000 words and sometimes even more if they want to reach native-like fluency. Similarly, Groot (2000: 62) argues that an adequate understanding of academic texts requires a vocabulary of at least 7,000 words. Generally, L2/FL readers need to recognize approximately 95 per cent of the words in a given text in order to comprehend its meaning and they need to know the different meanings of words according to context, as well as words' grammatical properties. In summary, it can be pointed out that reading and vocabulary are inter-related, in other words, good readers have a rich vocabulary, and similarly, a rich vocabulary is one of the key elements that ensure reading proficiency.It has been increasingly argued that computer technologies can support learning in a number of ways. Many features of the computer are considered to enhance vocabulary development and reading comprehension: multimedia is one of them. Multimedia refers to computerbased systems that use various types of content, such as text, audio, video, graphics, animation, and interactivity. The key concepts of multimedia are thus 'computer-based' and 'interactive'.Some research assessed the general value of ESL / EFL software programs for improving reading comprehension and vocabulary (AlKahtani, 1999; Busch, 2003; McGlinn and Parrish, 2002). More recent studies examined the effect of extended use of computers on reading achievement, the effect of computer instruction on reading rate and reading comprehension; the effects of multimedia software on reading comprehension and vocabulary acquisition, as well as the relationship between vocabulary development and reading comprehension (Singhal, 1998: 2-6). Most research on vocabulary acquisition and CALL has focused on the effects of multimedia glosses, and the same is true for reading comprehension, since vocabulary and reading are closely and reciprocally related. This reciprocal relationship also accounts for the fact that many research studies on vocabulary development and CALL also examine reading comprehension, and vice versa. One of the first to examine the effects of multimedia glosses for vocabulary development were Lyman-Hager and Davis (1996), who integrated a computer program into the French foreign language curriculum and discussed vocabulary acquisition and students' glossing choices for 262 intermediate level students studying French. Two conditions were used in this study: computerized reading and noncomputerized reading using an excerpt of Oyono's 'Une Vie de Boy'. Both groups had access to glosses: the computer group had access to multimedia annotations, whereas the control group could consult printed text with the same glosses. As to whether or not computer treatment offered significant benefits to FL students, the results of the written recall protocol indicated that the experimental group who used the computer program to read the text significantly outperformed the control group who used the glossed reading in the print form. 


\section{CONCLUSION}

Similarly, in an article exploring multimedia annotations and vocabulary acquisition, Chun and Plass (1996a) present the positive results of three studies with students in their second year of German who used Cyberbuch, a multimedia application offering various types of annotations (picture, text, video). The goals of this study included the exploration of incidental vocabulary learning, and the examination of the effectiveness of multimedia annotations on vocabulary acquisition. The results of this case study supported previous research on the effectiveness of different types of annotations, according to which visual imagery was found to help in learning and retention of new foreign words. Moreover, visual multimedia advance organizers were found to help not only recalling new words, but also act as facilitators of reading comprehension, which stresses the close relationship between vocabulary and reading (Chun and Plass, 1996b: 512). Text+picture annotations produced the best results in the recall protocol focusing on reading comprehension.

\section{REFERENCES}

1. Aebersold, J.A. and M. L. Field. (1997) From Reader to Reading Teacher. Issues and strategies for second language classrooms. Cambridge University Press.

2. AlKahtani, S. (1999). Teaching ESL Reading Using Computers. The Internet TESL Journal, V (11). http://iteslj.org/Techniques/AlKahtani-ComputerReading/

3. Anderson, N. (1999) Exploring Second Language Reading. Issues and Strategies. Boston: Heinle \&Heinle Publishers.

4. Busch, H.-J. (2003) Computer Based Readers for Intermediate Foreign-Language Students. Educational Media International, 40 (3-4), pp. 277-185.

5. Butler-Pascoe, M. E. and K. M. Wiburg. (2003) Technology and Teaching English Language Learners. Pearson Education, Inc. pp. 114-137.

6. Brett, A \& Rothlein, L. (1996). Vocabulary acquisition from listening to stories and explanations of target Words. The Elementary School Journal, (96) 4,67-85.

7. Balochowicz, C. \& Fisher, P. (2000). Teaching Vocabulary. Manhwah, NJ: Erlbaum Brown, T. S. \& Perry, F. L. (1991). A comparison for three languagestrategies for ESL vocabulary acquisition. TESOL Quarterly, (25).4, 655-670

8. Chun, D.M. (1996). Effects of multimedia annotations on vocabulary acquisition. The Modern Language Journal, (80)2, 65-80. 